\title{
Multi-type Air Pollutant Emission Inventory of Non-road Mobile Sources in China for the Period 1990-2017
}

\author{
Xianbao Shen ${ }^{1,2,3}$, Lei Kong ${ }^{3}$, Yue Shi ${ }^{3}$, Xinyue Cao ${ }^{1,2,3}$, Xin $\mathrm{Li}^{1,2,3}$, Bobo $\mathrm{Wu}^{1,2,3}$, \\ Hanyu Zhang ${ }^{1,2,3}$, Zhiliang Yao ${ }^{1,2,3^{*}}$ \\ ${ }^{1}$ State Environmental Protection Key Laboratory of Food Chain Pollution Control, Beijing \\ Technology and Business University, Beijing 100048, China \\ ${ }^{2}$ Key Laboratory of Cleaner Production and Integrated Resource Utilization of China National \\ Light Industry, Beijing Technology and Business University, Beijing 100048, China \\ ${ }^{3}$ School of Ecology and Environment, Beijing Technology and Business University, Beijing \\ 100048, China
}

\section{ABSTRACT}

With the increasingly strict supervision of road mobile sources and the ongoing progress in research, the relative contribution of non-road mobile sources to the total emissions has grown in prominence. Therefore, accurately estimating the emissions from non-road mobile sources is essential to developing effective policies for improving air quality. Hence, this study established an inventory of nine air pollutants, viz., $\mathrm{CO}, \mathrm{NO}_{\mathrm{x}}, \mathrm{HC}, \mathrm{PM}_{2.5}, \mathrm{PM}_{10}, \mathrm{BC}, \mathrm{OC}$, VOCs, and $\mathrm{SO}_{2}$, emitted by four types of non-road mobile sources, viz., construction machinery, agricultural machinery, vessels, and diesel locomotives, in China for the period 1990-2017. These emissions increased continually from 1990 till 2014, after which they decreased before increasing again during 2017. With the exception of $\mathrm{SO}_{2}$, which primarily originated from vessels, agricultural machinery accounted for the largest proportion of emissions for all of the pollutants, contributing $67.7 \%$ $(1472.5 \mathrm{Gg})$ and $46.1 \%(2170.4 \mathrm{Gg})$ of the total $\mathrm{CO}$ and $\mathrm{NO}_{\mathrm{x}}$ from non-road mobile sources, respectively. Additionally, the spatial distribution of the investigated pollutants revealed high concentrations on the North China Plain and in the Southeast China coastal area. Our findings demonstrate the necessity of improving the registration system for non-road mobile sources as well as the urgency of obtaining accurate emission factors for them by further researching their emission characteristics.

Received: January 7, 2021

Revised: May 6, 2021

Accepted: May 31, 2021

Keywords: Non-road, Emission inventory, Multiple pollutants, China

${ }^{*}$ Corresponding Author: yaozhl@th.btbu.edu.cn

\section{Publisher:}

Taiwan Association for Aerosol Research

ISSN: $1680-8584$ print

ISSN: 2071-1409 online

Copyright: The Author(s). This is an open access article distributed under the terms of the Creative Commons Attribution License (CC BY 4.0), which permits unrestricted use, distribution, and reproduction in any medium, provided the original author and source are cited.

\section{INTRODUCTION}

With the continuous development of operations to prevent and control air pollution in China, the Blue-Sky Protection Campaign has achieved remarkable results (Ding et al., 2019; Zhang et al., 2019). But the current level of atmospheric pollution remains of considerable concern. The mobile source emissions have become an important source of air pollution in China (MEPC, 2018).

The mobile source is usually divided into two categories: road mobile sources and non-road mobile sources (Zawacki et al., 2018). In recent years, vehicle emissions have received considerable attention in China (Liu et al., 2017; Yang et al., 2018; Gu et al., 2019). Following in-depth research on vehicle emission characteristics and related control measures performed in China and many other countries, coupled with increasingly strict emission standards, control of road mobile source emissions has become increasingly effective (Wu et al., 2017). However, concurrently, the prominence of emissions from non-road mobile sources has increased (Dallmann and Harley, 2010). Non-road equipment, which mostly uses diesel and heavy oil as fuel, generally has a long 
service life and thus the implementation of emission standards has a lag (Cao et al., 2016). Moreover, there are significant deficiencies in the supervision and management of emissions from non-road mobile sources in China (Zhang et al., 2010). As non-road mobile sources are gradually becoming a major source of air pollution, measures for the prevention and control of such emissions must be emphasized and strengthened.

An air pollutant emission inventory is fundamental and prerequisite for air quality management. Earlier related research studies have shown that the proportion of mobile pollution emissions attributable to non-road mobile sources has become very prominent and has made significant contribution to air pollution in many coastal cities and major agricultural provinces. Kean et al. (2000) suggested that the use of diesel fuel in the engines of non-road equipment represents a substantial source of $\mathrm{NO}_{x}$ and $\mathrm{PM}_{10}$. Research by Zhang et al. (2006) showed that the total $\mathrm{PM}_{2.5}$ emissions of non-road equipment accounted for $56.7 \%$ of the total $\mathrm{PM}_{2.5}$ emissions of the entire mobile source in China in 2001. Lu et al. (2017) calculated the emissions of non-road mobile sources in Shanghai and Hangzhou in 2014. It was found that the emissions of non-road equipment accounted for $18.5 \%$ and $32.2 \%$, respectively, of total mobile source emissions. Li (2017) established a non-road emission inventory for China in 2013 and found that non-road equipment contributed $30 \%$ of $\mathrm{SO}_{2}$ and $\mathrm{NO}_{x}$ of mobile sources nationwide. To understand the characteristics of exhaust emissions from non-road mobile sources, previous studies used different methods to establish relevant emission inventories in different regions, which provided guidance for subsequent related research. However, previous studies rarely estimated the overall emission trend of different types of non-road equipment based on long temporal spans and broad spatial scales. Moreover, the range of pollutants considered was generally not sufficiently comprehensive. The time, region, and pollutant types of emission inventories established for non-road mobile sources since 2000 are summarized in Table S1 (in the supplementary material).

In the early years, researchers often used methods based on fuel consumption to calculate pollutant emissions from non-road mobile equipment (Wang et al., 2016). To improve the accuracy of emission inventories, several studies used power-based calculation methods to calculate the pollutant emissions of different types of non-road equipment, for example, using a power-based calculation method to estimate the pollutant emissions of non-road equipment (Jiang et al., 2019). Such an approach depends on the acquisition of activity data, and when activity data are incomplete or cannot meet the requirements of the calculation method, the power-based calculation method is difficult to apply in relation to non-road equipment. When the research scope is small, researchers often use field-based research methods to obtain relevant activity data to meet the requirements of different calculation methods and to establish a more accurate emission inventory (Bian et al., 2018). Conversely, when the research scope is large, it is difficult to obtain activity data through field-based research, and the question of how best to obtain activity data that could meet the requirements of the calculation method becomes a notable problem. It is evident that substantial deficiencies remain in research on non-road mobile sources in China, and huge data gaps exist in all aspects of the formulation of emission inventories (Wang et al., 2016).

This study established an emission inventory of non-road equipment in China for the period 1990-2017. Nine types of pollutants typically emitted by such equipment were estimated: $C O$, $\mathrm{NO}_{x}, \mathrm{HC}, \mathrm{PM}_{2.5}, \mathrm{PM}_{10}, \mathrm{BC}, \mathrm{OC}, \mathrm{VOCs}$, and $\mathrm{SO}_{2}$. The first-level classification of non-road equipment is divided into construction machinery, agricultural machinery, vessels, diesel locomotives, small general-purpose machinery, diesel generator sets and commercial aircrafts. Small general-purpose machinery, diesel generator sets and commercial aircrafts account for a relatively small amount of pollutant emissions (MEPC, 2014; Desouza et al., 2020). Moreover, a complete registration and filing system has not yet been established in China, which leads to a lack of relevant activity data and the lack of research. Therefore, in this study, four types of non-road equipment (agricultural machinery, construction machinery, vessels, and diesel locomotives) were focused on. Compared with previous studies, this study used different data processing methods to improve the completeness and accuracy of activity data. Different methods were used to calculate the pollutant emissions of different types of non-road equipment. Moreover, according to the different calculation methods, this study selected the most appropriate emission factors to reduce the level of uncertainty of the emission inventory. We analysed the changing trends and emission contributions of different pollutants associated with different non-road equipment to provide a reference for air quality management and policy formulation in relation to non-road mobile sources. 
Non-road mobile equipment was divided into four categories: construction machinery, agricultural machinery, vessels and diesel locomotives. The related activities, emissions factors, and calculation methods were collected and analysed based on publicly available technical reports, global databases, journal papers, and national yearbook statistics (Tables S2-S5). Various methods were adopted to process the different types of data and to estimate the emissions of the non-road equipment.

Compared with previous studies, the approach adopted in this study was markedly different in terms of activity data. Survival curves were used to estimate the population of various types of agricultural machinery with different emission standards, thereby improving the accuracy of the activity data. In addition, this study supplemented missing activity data through curve fitting, which improved the integrity of the activity data. Furthermore, the selection of emission factors is determined by the calculation method. Moreover, the impact of different emission standards on pollutant emissions was taken into account when calculating agricultural machinery emissions. Most importantly, using the same calculation method for the same type of equipment over a longer period can help reduce uncertainty in an emission inventory.

\subsection{Classification of Non-road Equipment}

This study further divided the non-road equipment categories based on the collected activity data. Agricultural machinery was classified based on the Non-road Mobile Source Emissions Inventory Compiled Technical Guidelines (MEPC, 2014) and the type of activity data collected. Since pollutant emissions from fishing vessels could cause serious harm to local atmospheric environment quality (Liu et al., 2018) but were often ignored in previous studies, this study included such emissions in the calculation range of vessel-related pollutant emissions. The specifics of the full classification are listed in Table 1.

\subsection{Activity Data}

This study collated data on the activity during 1990-2017 of the four types of non-road equipment in 31 different provinces and cities in China. Through examining local statistical yearbooks, searching statistical databases, performing curve fitting on existing data, and using provincial/municipal data within national data archives in adjacent years, we obtained a complete dataset on non-road mobile sources in China during 1990-2017.

\subsubsection{Construction machinery}

It was difficult to obtain accurate data on the activity of construction machinery through field investigation in this study owing to the lack of such data in many different provinces and cities in China, and the wide spatial coverage and long time span. Therefore, diesel consumption was estimated according to the power of construction machinery. The activity data types and sources

Table 1. Classification of non-road equipment.

\begin{tabular}{lllll}
\hline Class & Construction machinery & Agricultural machinery & Vessels & Diesel locomotives \\
\hline 1 & Construction machinery & $\begin{array}{c}\text { Larger and medium-sized } \\
\text { tractor }\end{array}$ & Inland river passenger vessel & Passenger diesel locomotive \\
& Small tractor & Inland river cargo vessel & Freight diesel locomotive \\
3 & Agricultural drainage and & Coastal passenger vessel & \\
& irrigation machinery & & \\
5 & Harvesting machine & Coastal cargo vessel & \\
6 & Others & Fishing vessel & \\
7 & Three-wheeled transport & & \\
& vehicle & & \\
& Low-speed truck &
\end{tabular}

a Diesel-powered agricultural drainage and irrigation machinery.

${ }^{\mathrm{b}}$ All agricultural machinery except the above six types and fishing vessels. 
of construction machinery are shown in Table S2. Diesel consumption of construction machinery was calculated as shown in the supplementary material.

\subsubsection{Agricultural machinery}

To estimate the emissions of agricultural machinery more accurately, this study subdivided the category into seven different types based on the collected activity data (Table S3). Diesel consumption of agricultural machinery was calculated as shown in the supplementary material.

To meet the requirements for calculation methods that are more accurate, this study classified different types of agricultural machinery according to emission standards. As the implementation of emission standards for non-road equipment is lagging, for the sake of calculation, this study assumed a lag period of two years. The actual and lagged times of emission standards implementation are shown in Tables S6 and S7. New machines produced after the lagged years of emission standards were assumed to meet all the new emission standards (Sun et al., 2016).

In this study, the method of survival curves was used to simulate the distribution of agricultural machinery retention with different emission standards. The method has been used widely in simulations of the survival probability of motor vehicles (Lin et al., 2019). The survival probability of machines is shown in Eq. (1):

$\varphi_{i, j(k)}=\frac{n_{i, j(k+1)}}{n_{0, j(k)}}$

where $\varphi_{i, j(k)}$ refers to the number of new machines of type $j$ in $k$ years (vehicle age $i=0$ ), and $n_{i, j(k+i)}$ refers to the number of machines of type $j$ that remain in normal use in $k+i$ years.

On the premise that mechanical properties, scrappage laws, and other external conditions do not change, it can be considered that the mechanical survival curve of each year remains unchanged. Under this premise, the variation of mechanical survival probability with mechanical age conforms to a two-parameter Weibull distribution (Zachariadis et al., 1995). The Weibull distribution adopted in this paper is shown in Eq. (2):

$\varphi_{i, j}=\exp \left[-\left(\frac{i+b_{i}}{T_{i}}\right)^{b j}\right] \quad(i=0,1, \ldots ., m-1)$

where $\varphi_{i, j}$ is the surviving number of type $j$ machines of mechanical age $i, i$ is the time in years (e.g., 0 for 1990 and 27 for 2017), $T$ is the service life of machine type $j$, and $b$ is a parameter of the function.

The numbers of agricultural machinery by the survival curve are shown in Fig. 1. As it is difficult to use a calculation method based on population for other agricultural machinery diesel engines, this study adopted a power-based method to calculate such emissions. The method used for calculation of the power of other agricultural machinery diesel engines is shown in the supplementary material.

\subsubsection{Vessels}

Vessels make a considerable contribution to non-road pollutant emissions in coastal provinces and cities, and areas with a developed fishing and shipping industry (Xie and Zheng, 2016). Thus, this study investigated the pollutant emissions of inland river passenger and cargo vessels, coastal passenger and cargo vessels, and fishing vessels. The data types and sources of vessel activity dates are shown in Table S4. Fishing vessels and inland river vessels are generally powered by diesel, while coastal vessels are mainly powered by fuel oil (Song, 2015). The method for calculation of the fuel consumption of vessels is shown in the supplementary material.

\subsubsection{Diesel locomotives}

The pollutant emissions of railway locomotives are derived mainly from diesel locomotives (He et al., 2010). Therefore, when considering pollutant emissions from railway locomotives, this study mainly calculated the pollutant emissions of diesel locomotives. The activity data of diesel 

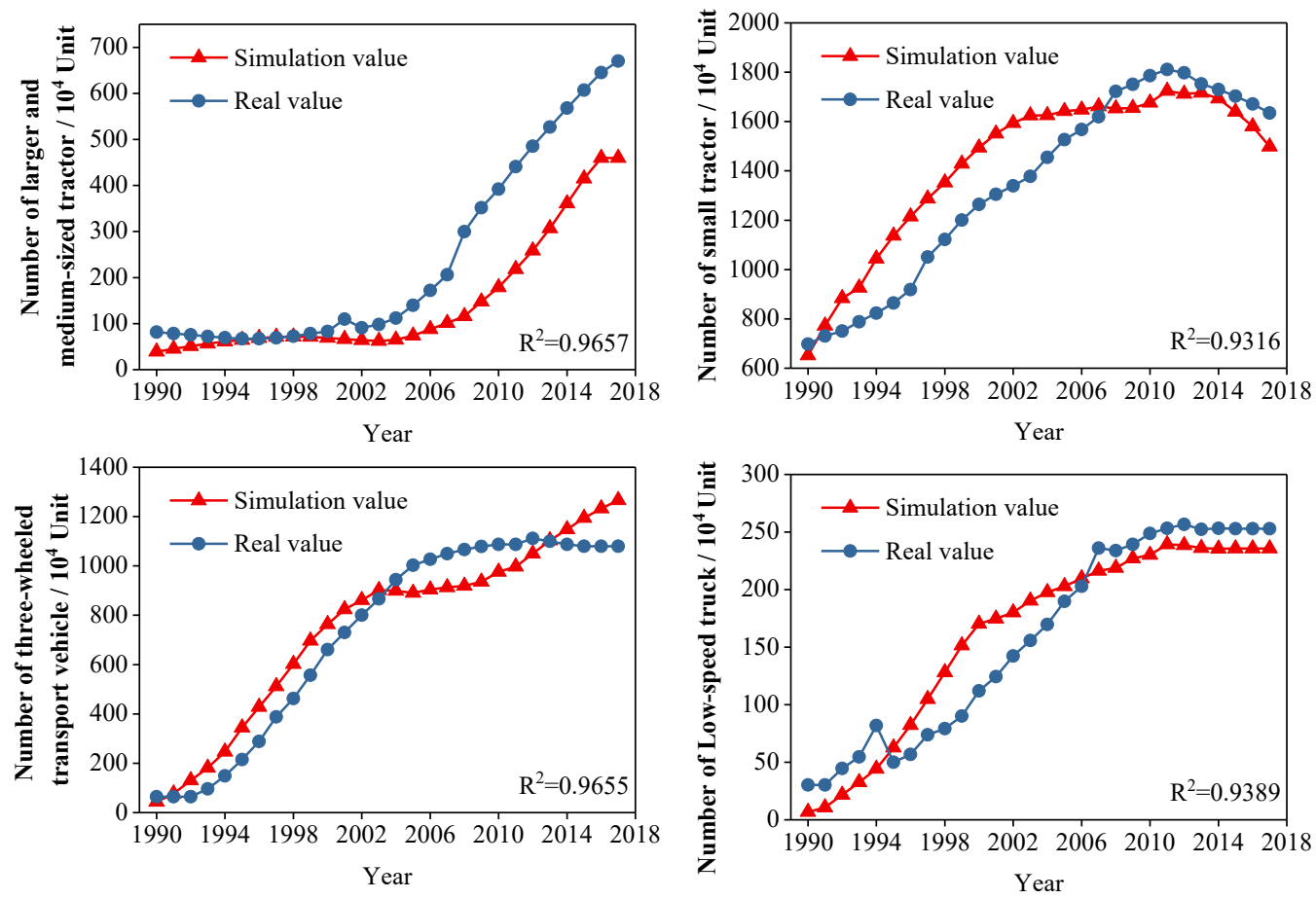

Fig. 1. Numbers of agricultural machines.

locomotives include both passenger and freight diesel locomotives. The data types and sources of diesel locomotive activity are shown in Table S5. The method for calculation of the fuel consumption of diesel locomotives is shown in the supplementary material (He et al., 2010).

\subsection{Emission Factors and Calculations}

To meet the requirements of different calculation methods, emission factors based on fuel consumption, power, and mileage were collected in this study. The emission factors are listed in Tables 2-4 (MEPC, 2014; He et al., 2017).

Owing to the different types of activity data obtained, four different methods were adopted in this study for calculation of the pollutant emissions by different types of non-road equipment, as presented in the supplementary material.

\section{RESULTS AND DISCUSSION}

\subsection{Emission Inventory of Non-road Mobile Sources in China}

\subsubsection{Overall temporal trends}

An overview of the interannual variations in emissions of $\mathrm{CO}, \mathrm{NO}_{x}, \mathrm{HC}, \mathrm{PM}_{2.5}, \mathrm{PM}_{10}, \mathrm{BC}, \mathrm{OC}, \mathrm{VOCs}$, and $\mathrm{SO}_{2}$ and the fuel consumption of non-road mobile sources during 1990-2017 is presented in Fig. 2. Annual emissions of $\mathrm{CO}, \mathrm{NO}_{\mathrm{x}}, \mathrm{HC}, \mathrm{PM}_{2.5}, \mathrm{PM}_{10}, \mathrm{BC}, \mathrm{OC}$, and VOCs from non-road mobile

Table 2. Fuel-based emission factors for other non-road equipment (except agricultural machinery).

\begin{tabular}{|c|c|c|c|c|c|c|c|c|}
\hline \multirow{2}{*}{ Class } & \multicolumn{8}{|c|}{ Emissions factor (g kg-fuel ${ }^{-1}$ ) } \\
\hline & $\mathrm{CO}$ & $\mathrm{NO}_{\mathrm{x}}$ & $\mathrm{HC}$ & $\mathrm{PM}_{2.5}$ & $\mathrm{PM}_{10}$ & $\mathrm{BC}$ & OC & VOCs \\
\hline Construction machinery & 10.72 & 32.79 & 3.39 & 2.09 & 2.09 & 1.50 & 0.47 & 5.34 \\
\hline Diesel locomotives & 8.29 & 55.73 & 3.11 & 1.97 & 2.07 & 1.12 & 0.35 & 3.11 \\
\hline Inland river vessel (diesel) & 23.80 & 47.60 & 6.19 & 3.65 & 3.81 & 2.08 & 0.66 & 6.19 \\
\hline Coastal vessel (fuel) & 7.40 & 79.30 & 2.70 & 5.60 & 6.20 & 2.08 & 0.66 & 6.19 \\
\hline Fishing vesse $\mathrm{l}^{\mathrm{a}}$ & 15.60 & 63.45 & 4.45 & 4.63 & 5.00 & 2.08 & 0.66 & 6.19 \\
\hline
\end{tabular}

${ }^{a}$ The average emission factor of vessels was used to estimate the emissions of fishing vessels (Ye et al., 2014). 
Table 3. Power-based emission factors for agricultural machinery.

\begin{tabular}{|c|c|c|c|c|c|c|c|c|c|}
\hline \multirow{2}{*}{$\begin{array}{l}\text { Engine power } \\
(\mathrm{kW})\end{array}$} & \multirow{2}{*}{$\begin{array}{l}\text { Emission } \\
\text { standard }\end{array}$} & \multicolumn{8}{|c|}{ Emissions factor $\left(\mathrm{g} \mathrm{kWh}^{-1}\right)$} \\
\hline & & $\mathrm{CO}$ & $\mathrm{NO}_{\mathrm{x}}$ & $\mathrm{HC}$ & $\mathrm{PM}_{2.5}$ & $\mathrm{PM}_{10}$ & $\mathrm{BC}$ & OC & VOCs \\
\hline \multirow[t]{4}{*}{$G<37$} & Pre-Stage I & 6.50 & 10.5 & 1.30 & 1.14 & 1.20 & 0.65 & 0.21 & 1.30 \\
\hline & Stage I & 6.50 & 10.5 & 1.30 & 0.95 & 1.00 & 0.54 & 0.17 & 1.30 \\
\hline & Stage II & 6.50 & 7.50 & 1.30 & 0.90 & 0.95 & 0.51 & 0.16 & 1.30 \\
\hline & Stage III & 5.00 & 6.00 & 1.10 & 0.52 & 0.55 & 0.30 & 0.09 & 1.30 \\
\hline \multirow[t]{4}{*}{$37<\mathrm{G}<75$} & Pre-Stage I & 6.50 & 10.5 & 1.30 & 0.95 & 1.00 & 0.54 & 0.17 & 1.10 \\
\hline & Stage I & 6.50 & 9.20 & 1.30 & 0.81 & 0.85 & 0.46 & 0.15 & 1.30 \\
\hline & Stage II & 5.00 & 7.00 & 1.30 & 0.38 & 0.40 & 0.22 & 0.07 & 1.30 \\
\hline & Stage III & 4.50 & 3.50 & 1.00 & 0.32 & 0.35 & 0.18 & 0.06 & 1.00 \\
\hline \multirow[t]{4}{*}{$75<\mathrm{G}<130$} & Pre-Stage I & 5.00 & 10.0 & 1.30 & 0.76 & 0.80 & 0.43 & 0.14 & 1.30 \\
\hline & Stage I & 5.00 & 9.20 & 1.30 & 0.67 & 0.70 & 0.38 & 0.12 & 1.30 \\
\hline & Stage II & 5.00 & 6.00 & 1.00 & 0.29 & 0.30 & 0.17 & 0.05 & 1.00 \\
\hline & Stage III & 4.50 & 2.80 & 0.80 & 0.23 & 0.25 & 0.13 & 0.04 & 0.80 \\
\hline \multirow[t]{4}{*}{$G>130$} & Pre-Stage I & 5.00 & 10.0 & 1.30 & 0.67 & 0.70 & 0.38 & 0.12 & 1.30 \\
\hline & Stage I & 5.00 & 9.20 & 1.30 & 0.51 & 0.54 & 0.29 & 0.09 & 1.30 \\
\hline & Stage II & 3.50 & 6.00 & 1.00 & 0.19 & 0.20 & 0.11 & 0.03 & 1.00 \\
\hline & Stage III & 3.00 & 2.80 & 0.80 & 0.16 & 0.18 & 0.09 & 0.03 & 0.80 \\
\hline
\end{tabular}

Table 4. Mileage-based emission factors for agricultural transport vehicles.

\begin{tabular}{|c|c|c|c|c|c|c|c|c|c|}
\hline \multirow{2}{*}{ Class } & \multirow{2}{*}{$\begin{array}{l}\text { Emission } \\
\text { standard }\end{array}$} & \multicolumn{8}{|c|}{ Emissions factor $\left(\mathrm{g} \mathrm{km}^{-1}\right)$} \\
\hline & & $\mathrm{CO}$ & $\mathrm{NO}_{\mathrm{x}}$ & $\mathrm{HC}$ & $\mathrm{PM}_{2.5}$ & $\mathrm{PM}_{10}$ & $\mathrm{BC}$ & OC & VOCs \\
\hline \multirow{3}{*}{$\begin{array}{l}\text { Three-wheeled transport } \\
\text { vehicle }\end{array}$} & Pre-Stage I & 1.98 & 1.08 & 0.4 & 0.07 & 0.08 & 0.04 & 0.01 & 0.40 \\
\hline & Stage I & 0.95 & 1.07 & 0.24 & 0.06 & 0.07 & 0.03 & 0.01 & 0.24 \\
\hline & Stage II & 0.75 & 0.87 & 0.16 & 0.05 & 0.05 & 0.03 & 0.01 & 0.16 \\
\hline \multirow[t]{3}{*}{ Low-speed truck } & Pre-Stage I & 4.52 & 3.95 & 1.32 & 0.18 & 0.19 & 0.10 & 0.03 & 1.32 \\
\hline & Stage I & 2.62 & 3.88 & 1.16 & 0.16 & 0.17 & 0.09 & 0.03 & 1.16 \\
\hline & Stage II & 2.06 & 3.14 & 0.75 & 0.12 & 0.13 & 0.07 & 0.02 & 0.75 \\
\hline
\end{tabular}

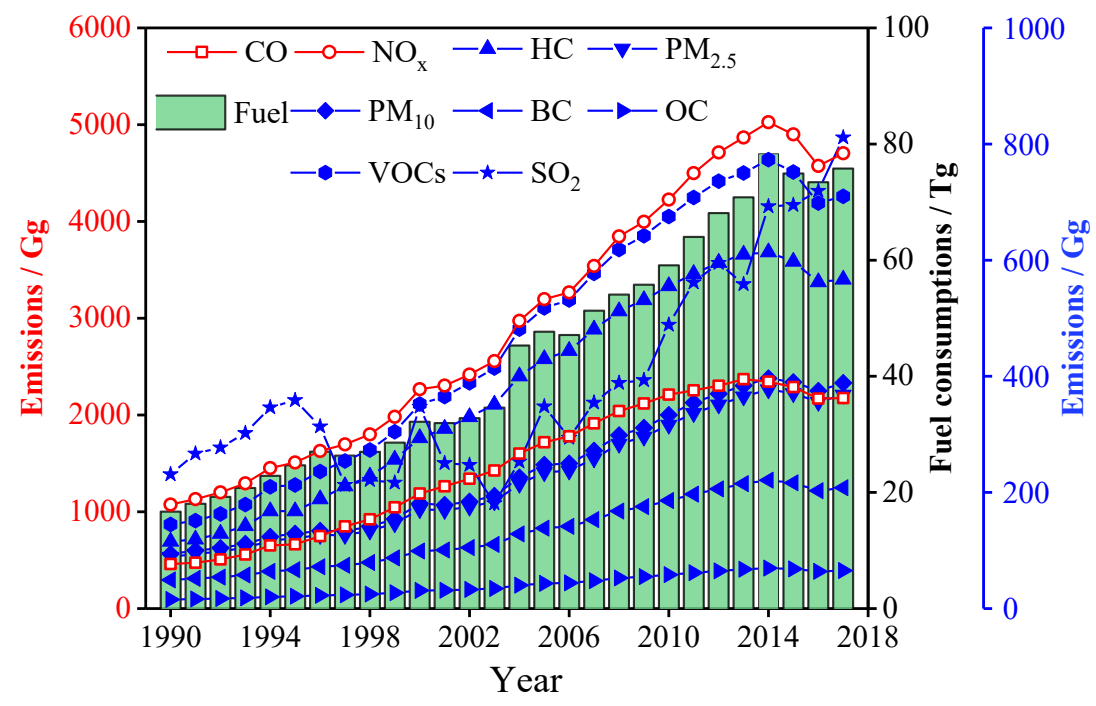

Fig. 2. Emissions of $\mathrm{CO}, \mathrm{NO}_{x}, \mathrm{HC}, \mathrm{PM}_{2.5}, \mathrm{PM}_{10}, \mathrm{BC}, \mathrm{OC}, \mathrm{VOCs}$, and $\mathrm{SO}_{2}$ and amount of fuel consumption of non-road mobile sources in China (1990-2017).

sources increased obviously during 1990-2014 and then declined gradually thereafter. The trends of the emissions of these eight pollutants were generally consistent with that of fuel consumption. This shows that with the rapid economic development, the degree of mechanization 
in agriculture and construction continues to increase, and the use of non-road mobile equipment is becoming more and more frequent, which has led to a continuous increase in emissions from non-road mobile sources (Jiang et al., 2020; Hong et al., 2021). On the contrary, emissions from non-road mobile sources have gradually declined in recent years, reflecting the substantial effect of the multiple efforts implemented to control emissions of these pollutants from non-road mobile sources. However, increasing rates of agricultural and industrial mechanization led to a resurgence in the level of emissions of these pollutants in 2017, which deserves our attention. The change in $\mathrm{SO}_{2}$ emissions has experienced many fluctuations. The emission of this pollutant is mainly from coastal cargo vessels, and the trend of its variation is similar to that of the change in turnover of coastal cargo vessels. Emissions of $\mathrm{SO}_{2}$ from coastal cargo vessels usually account for $>80 \%$ of total $\mathrm{SO}_{2}$ emissions. This is because coastal cargo vessels often use heavy oil with high sulphur content as fuel (Song, 2015), and coupled with the increasingly strict emission standards for vehicle diesel, their $\mathrm{SO}_{2}$ emissions are much higher than those of other non-road equipment. The above results indicate that measures that are more stringent are needed to reduce emissions from non-road mobile sources.

The emission inventory of non-road mobile sources in China in 2017 was the latest result of this study and the result is shown in Table S9. The total emissions of $\mathrm{CO}, \mathrm{NO}_{x}, \mathrm{HC}, \mathrm{PM}_{2.5}, \mathrm{PM}_{10}$, BC, OC, VOCs, and $\mathrm{SO}_{2}$ from non-road mobile sources in 2017 in China were estimated at approximately $2176,4704,567,368,388,208,65.5,710$, and $811 \mathrm{Gg}$, respectively. The emissions of $\mathrm{HC}, \mathrm{NO}_{x}$, and PM were approximately $12 \%, 41 \%$, and $39 \%$, respectively, in comparison with the emissions from mobile sources estimated in the China Vehicle Environmental Management Annual Report (MEPC, 2018). Moreover, with the increasingly strict supervision of road mobile sources and the continuous deepening of research (Li et al., 2020; Sun et al., 2021), coupled with the increasingly stringent emission standards, the effectiveness of vehicle emission control has become increasingly significant, and on-road mobile source emissions have been effectively supervised (Zhang et al., 2020). However, there are still significant deficiencies in the basic research of non-road mobile sources, resulting in non-road mobile sources gradually becoming an important source of air pollution emissions, and their emission reduction status is also increasingly prominent (Cao et al., 2016). What is more serious is that in the next five years, China will add more than 1.6 million construction machinery, and the total diesel power of agricultural machinery is more than $150 \mathrm{gW}$ (MEPC, 2018), indicating that non-road equipment has become a non-negligible source of atmospheric pollutants.

\subsubsection{Spatial distribution}

Owing to the huge differences in terms of the economic development, technical level, geographical location, and industrial composition of non-road mobile sources in various provinces and cities in China, the difference in pollutant emissions from different non-road equipment is very large. Fig. 3 illustrates the spatial distributions of the emissions of each of the studied pollutants from non-road mobile sources in 1990 and 2017. Through 27 years of development, China has accomplished world-renowned achievements in many fields such as agriculture, construction, and transportation. However, concurrently, emissions of pollutants from non-road mobile sources increased substantially, especially in provinces with highly developed agriculture, construction, and transportation, e.g., Shandong, Henan, Jiangsu and Zhejiang Provinces. Henan, Shandong and Jiangsu Provinces accounted for the top three in total agricultural output value in China in 2017, while the total output value of the construction industry in Jiangsu and Zhejiang Provinces is far ahead of other provinces (NBS, 2018). This has resulted in higher non-road emissions in the North China Plain and Southeast China coastal area than in other regions. The emissions of related air pollutants from non-road mobile sources are geographically dispersed. Nevertheless, there are several areas with high levels of air pollutant emissions from non-road mobile sources in China. As shown in Fig. 3, emissions of air pollutants from non-road mobile sources in the North China Plain and Southeast China coastal area in both 1990 and 2017 were evidently higher and more intensive than in other areas.

From the perspective of the rate of growth of pollutant emissions, the trends of $\mathrm{CO}, \mathrm{NO}_{\mathrm{x}}, \mathrm{HC}$, $\mathrm{PM}_{2.5}, \mathrm{PM}_{10}, \mathrm{BC}, \mathrm{OC}$, and VOC emissions were largely similar. During 1990-2017, the emissions of non-road mobile sources of air pollutants in China have generally increased by 3-5 times. 

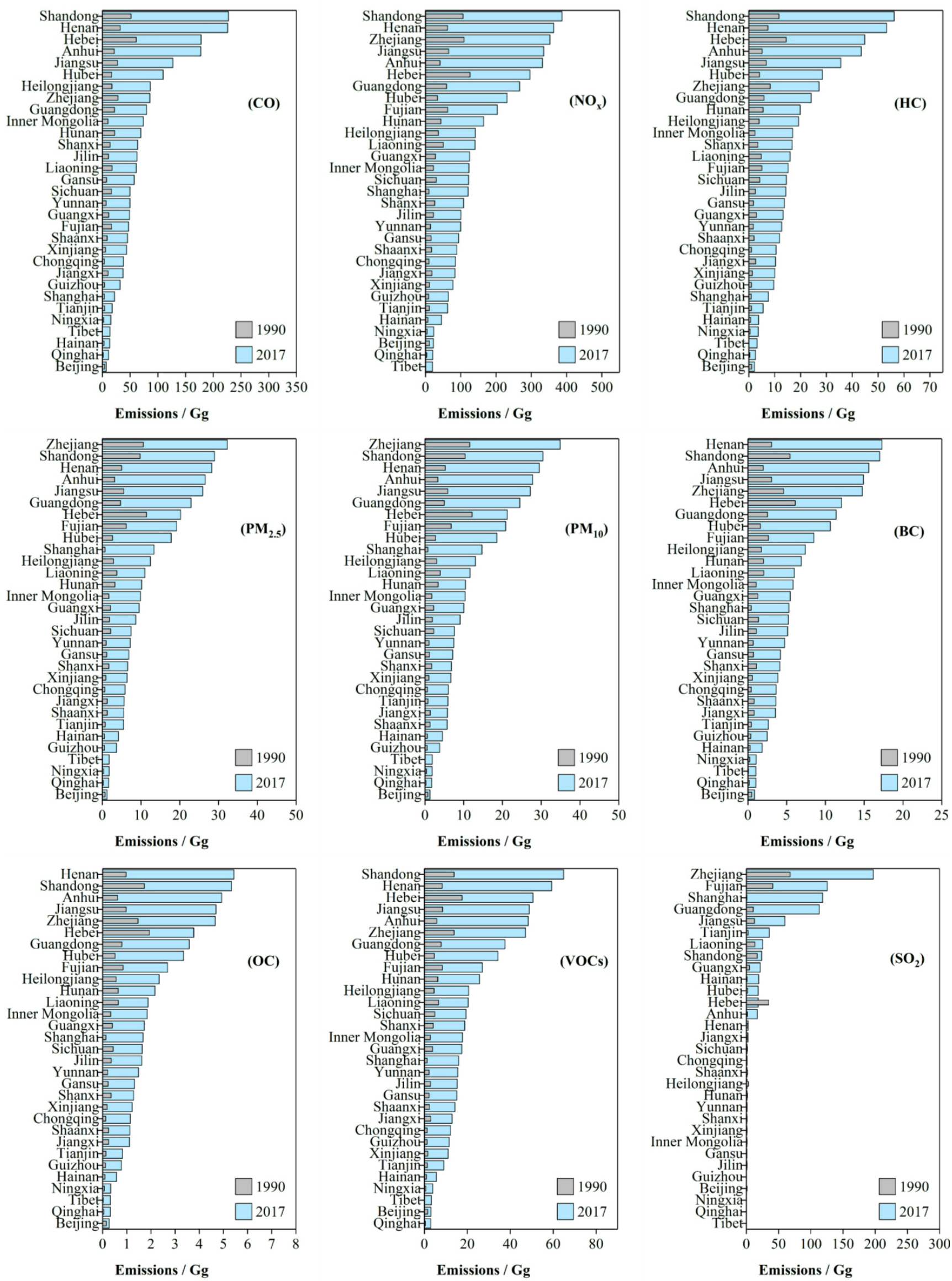

Fig. 3. Pollutant emissions from non-road mobile sources in different provinces in 1990 and 2017. 

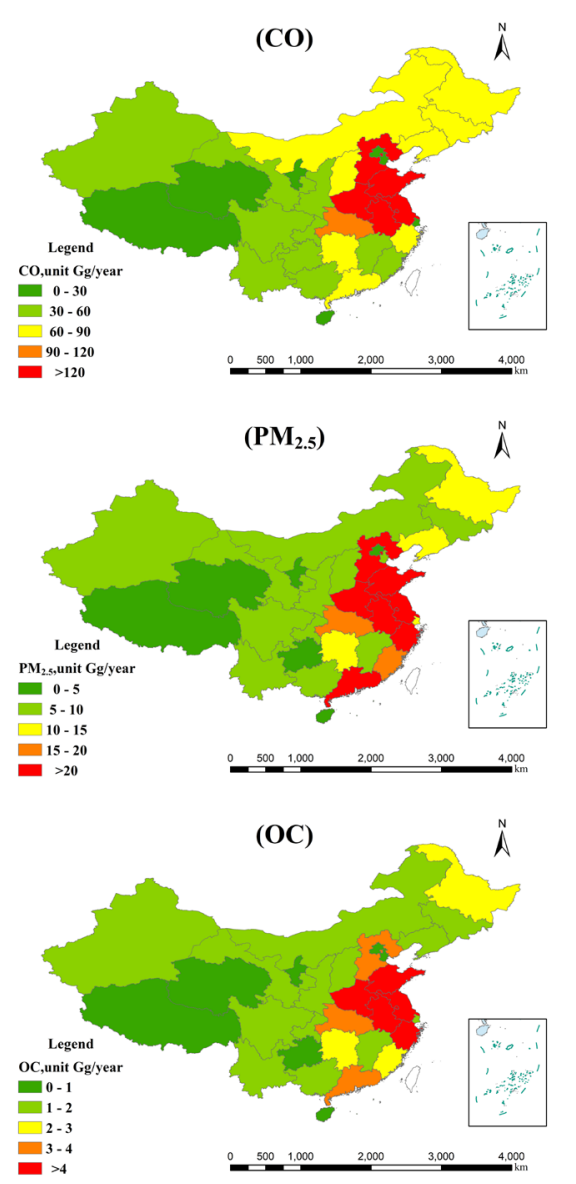
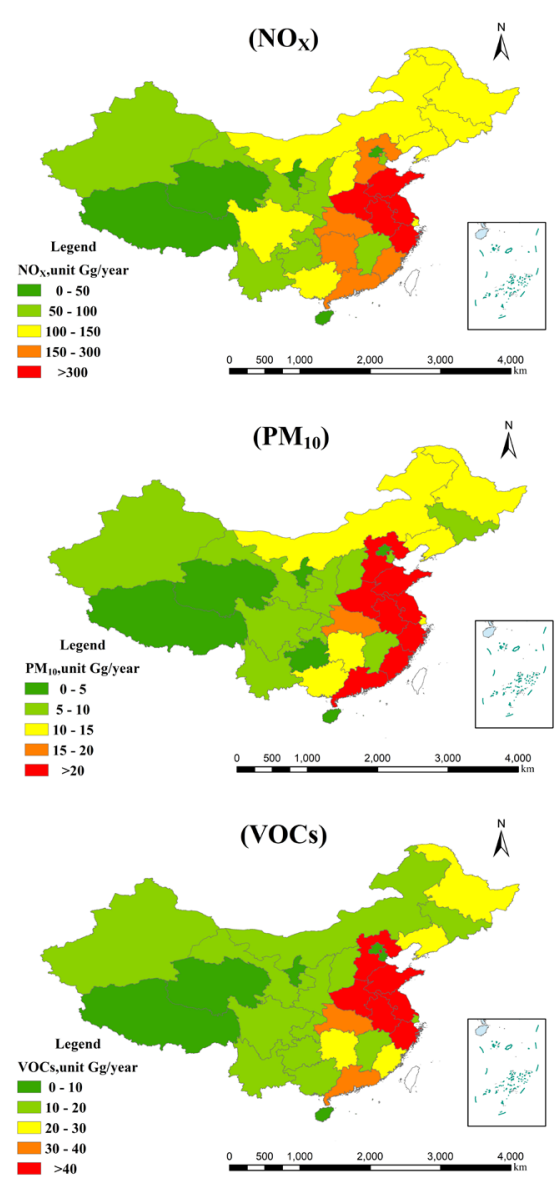
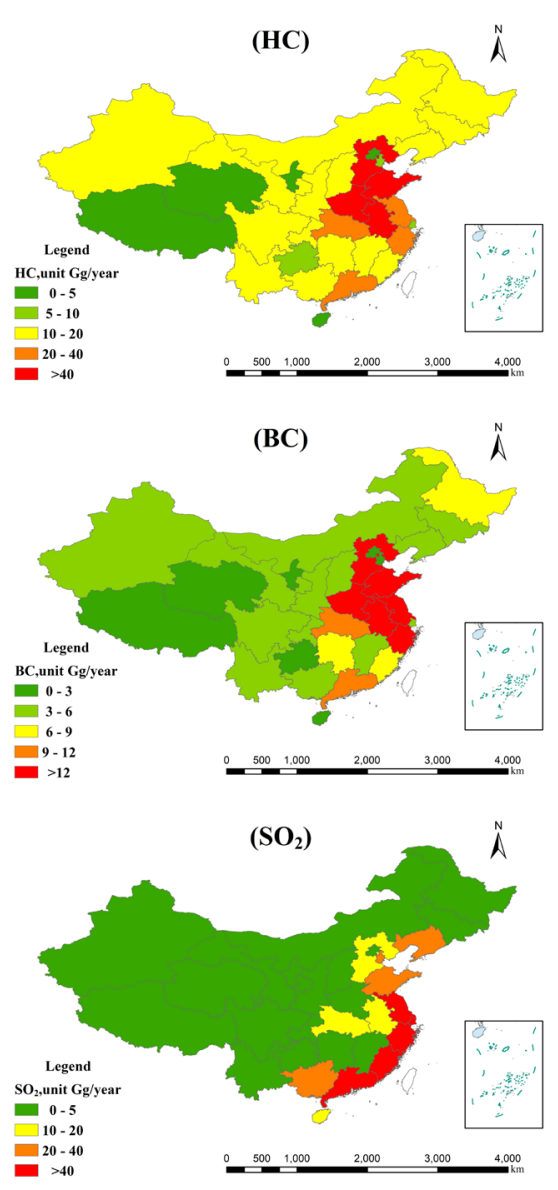

Fig. 4. Pollutant emissions per unit area from non-road mobile sources in China (2017).

Provincially, the changes of different air pollutants were not always consistent. For example, Shanghai was the province with the fastest rate of growth of $\mathrm{SO}_{2}$ emissions. Conversely, the change of $\mathrm{SO}_{2}$ emissions in Beijing showed the greatest trend of decline.

Maps of the spatial distribution of pollutant emissions in China in 2017 are presented in Fig. 4. Overall, the emissions in the North China Plain and Southeast China coastal area were higher than other areas. The reason is the population and activity data of the North China Plain and Southeast China coastal area were much higher than in southern and western regions, and their agriculture, industry, and transportation are also developing faster than other regions. Among them, the highest contributions of emissions were from Shandong Province, followed by Henan and Jiangsu Provinces. Additionally, Beijing, Qinghai, and Ningxia Provinces had the lowest emission intensities. The reasons for the disparities are strict emission control measures or low population and activity data.

\subsubsection{Emission contributions of sources}

Table 5 summarizes the emissions from non-road equipment for 1990, 2000, 2010, and 2017. Based on our estimates, the emissions of all pollutants (except $\mathrm{SO}_{2}$ ) from all four types of nonroad equipment increased substantially during 1990-2017. Conversely, emissions of $\mathrm{SO}_{2}$ from agricultural machinery decreased by $57 \%$.

Figs. 5 and 6 show the pollution emissions from non-road mobile sources and the contributions of each sector to the total emissions of the nine studied pollutants in China during 1990-2017. It can be seen that agricultural machinery was a major contributor to the emission of all pollutants (except $\mathrm{SO}_{2}$ ), accounting for approximately 49-83\% of total emissions. In comparison, construction machinery and vessels accounted for $26-53 \%$ and $27-46 \%$ of total $\mathrm{SO}_{2}$ emissions, respectively. Since 1990, with the rapid development of China's economy, China's construction industry has developed at a high rate and the total power of construction machinery has generally increased 
annually. However, since 2015, the total power of construction machinery in China has declined, as have the related pollutant emissions. At the same time, increasingly strict emission standards have also led to the decline in emissions from construction machinery, as confirmed by Pang et al. (2020).

China is a typical agricultural country. With the rapid development of agriculture and increasing agricultural mechanization in China, the emissions of pollutants from agricultural machinery

Table 5. Emissions (Gg) from non-road mobile sources in China in 1990, 2000, 2010, and 2017.

\begin{tabular}{|c|c|c|c|c|c|}
\hline & & 1990 & 2000 & 2010 & 2017 \\
\hline \multirow[t]{5}{*}{$\mathrm{CO}$} & Construction machinery & 32.3 & 85.1 & 232 & 306 \\
\hline & Agricultural machinery & 345 & 957 & 1734 & 1473 \\
\hline & Vessels & 67.9 & 112 & 193 & 360 \\
\hline & Diesel locomotives & 15.7 & 34.7 & 49.7 & 37.7 \\
\hline & Total & 461 & 1188 & 2210 & 2176 \\
\hline \multirow[t]{5}{*}{$\mathrm{NO}_{\mathrm{x}}$} & Construction machinery & 98.7 & 260 & 711 & 935 \\
\hline & Agricultural machinery & 574 & 1306 & 2384 & 2170 \\
\hline & Vessels & 297 & 467 & 798 & 1345 \\
\hline & Diesel locomotives & 105 & 234 & 334 & 253 \\
\hline & Total & 1075 & 2267 & 4227 & 4704 \\
\hline \multirow[t]{5}{*}{$\mathrm{HC}$} & Construction machinery & 10.2 & 26.9 & 73.5 & 96.7 \\
\hline & Agricultural machinery & 78.4 & 220 & 405 & 349 \\
\hline & Vessels & 20.9 & 33.8 & 58.4 & 107 \\
\hline & Diesel locomotives & 5.88 & 13.0 & 18.6 & 14.1 \\
\hline & Total & 115 & 294 & 556 & 567 \\
\hline \multirow[t]{5}{*}{$\mathrm{PM}_{2.5}$} & Construction machinery & 6.29 & 16.6 & 45.3 & 59.6 \\
\hline & Agricultural machinery & 49.8 & 102 & 183 & 170 \\
\hline & Vessels & 29.0 & 44.1 & 76.6 & 130 \\
\hline & Diesel locomotives & 3.72 & 8.25 & 11.8 & 8.96 \\
\hline & Total & 88.8 & 171 & 316 & 368 \\
\hline \multirow[t]{5}{*}{$\mathrm{PM}_{10}$} & Construction machinery & 6.29 & 16.6 & 45.3 & 59.6 \\
\hline & Agricultural machinery & 52.1 & 107 & 192 & 178 \\
\hline & Vessels & 31.8 & 48.2 & 83.7 & 142 \\
\hline & Diesel locomotives & 3.91 & 8.67 & 12.4 & 9.41 \\
\hline & Total & 94.1 & 181 & 333 & 388 \\
\hline \multirow[t]{5}{*}{$B C$} & Construction machinery & 4.51 & 11.9 & 32.5 & 42.8 \\
\hline & Agricultural machinery & 30.7 & 63.9 & 115 & 105 \\
\hline & Vessels & 11.9 & 18.4 & 32.0 & 55.4 \\
\hline & Diesel locomotives & 2.12 & 4.69 & 6.71 & 5.09 \\
\hline & Total & 49.2 & 98.9 & 186 & 208 \\
\hline \multirow[t]{5}{*}{ OC } & Construction machinery & 1.41 & 3.73 & 10.2 & 13.4 \\
\hline & Agricultural machinery & 9.78 & 19.9 & 35.8 & 32.9 \\
\hline & Vessels & 3.78 & 5.85 & 10.1 & 17.6 \\
\hline & Diesel locomotives & 0.66 & 1.47 & 2.10 & 1.59 \\
\hline & Total & 15.6 & 31.0 & 58.3 & 65.5 \\
\hline \multirow[t]{5}{*}{ VOCs } & Construction machinery & 16.1 & 42.4 & 116 & 152 \\
\hline & Agricultural machinery & 87.4 & 242 & 446 & 379 \\
\hline & Vessels & 35.4 & 54.8 & 95.2 & 165 \\
\hline & Diesel locomotives & 5.88 & 13.0 & 18.6 & 14.1 \\
\hline & Total & 145 & 352 & 675 & 710 \\
\hline \multirow[t]{5}{*}{$\mathrm{SO}_{2}$} & Construction machinery & 12.0 & 31.8 & 15.2 & 20.0 \\
\hline & Agricultural machinery & 18.2 & 33.3 & 8.34 & 7.85 \\
\hline & Vessels & 193 & 266 & 461 & 780 \\
\hline & Diesel locomotives & 7.56 & 16.8 & 4.20 & 3.18 \\
\hline & Total & 231 & 347 & 489 & 811 \\
\hline
\end{tabular}



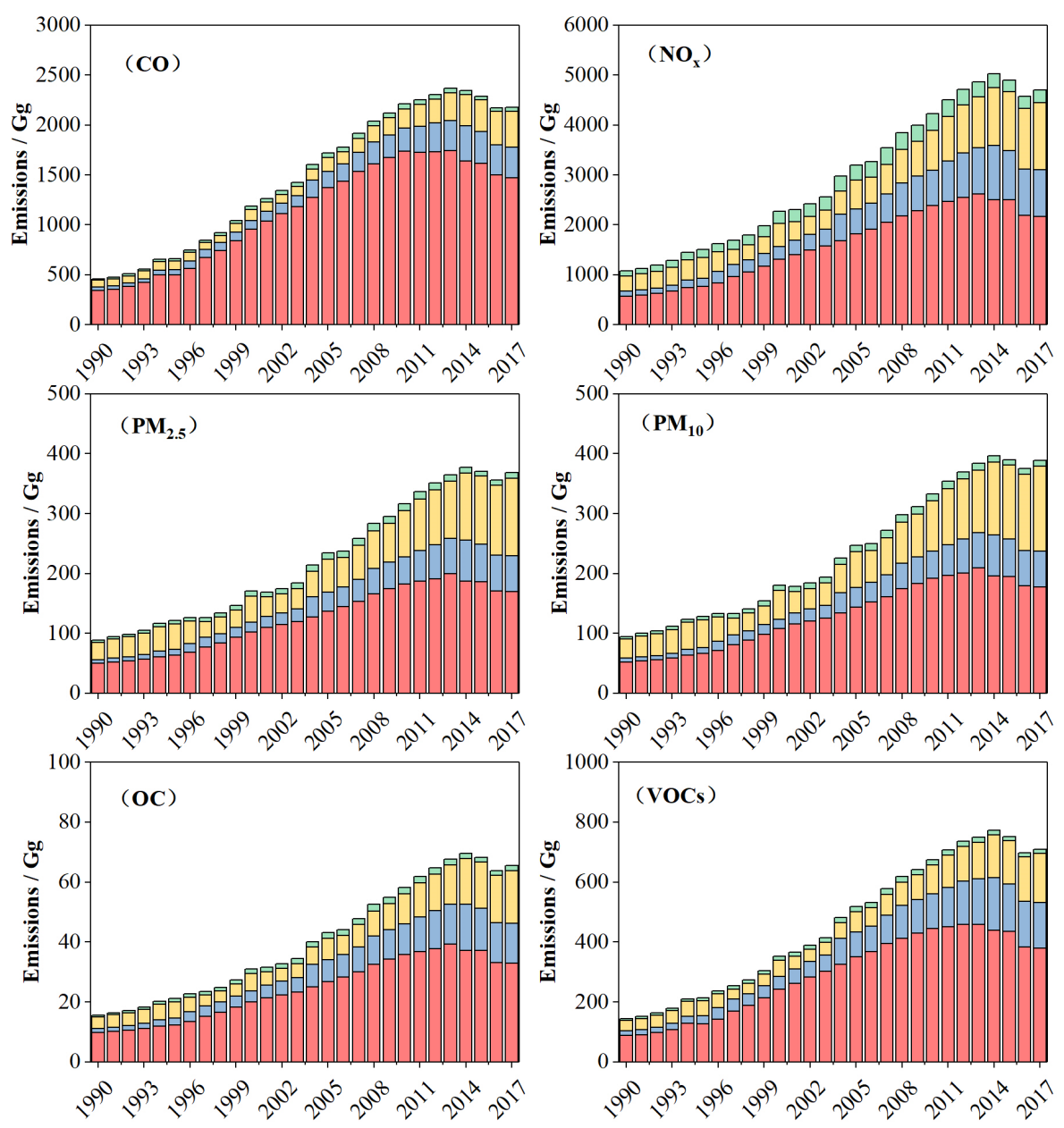
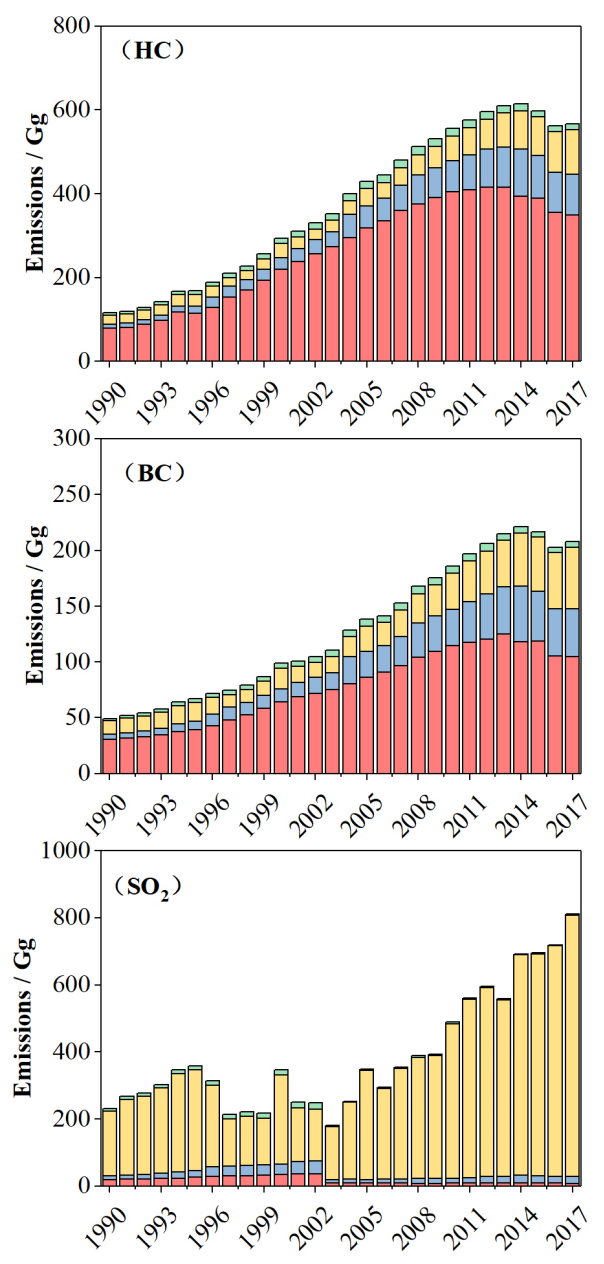

Vessel $\square$ Locomotive

Fig. 5. Pollutant emissions from non-road equipment in China (1990-2017).

increased rapidly during 1990-2011. However, since 2011, following the implementation of new emission standards for agricultural machinery, the rate of growth of related pollutant emissions has also slowed. Since 2014, with the promulgation of stricter emission standards, the emission of pollutants from agricultural machinery has shown a significant downward trend.

China is also a major shipping country. Owing to the scale of China's shipping economy, vessels also account for a high proportion of air pollutant emissions (Chen et al., 2017). According to the Yearbook of China Transportation \& Communications and China Agriculture Statistical Report, China's cargo turnover and the power of motorized fishing boats have increased annually. Inland river vessels and fishing boats mostly use inferior diesel as fuel, while coastal vessels mostly use heavy oil. In comparison with automotive diesel, low-quality diesel and heavy oil have higher sulphur content and both fuels can make substantial contributions to the emission of pollutants, especially $\mathrm{SO}_{2}$.

The variation of pollutant emissions from railway locomotives reflects the changes in passenger turnover and freight turnover. Passenger turnover increased annually during 1990-2017, while freight turnover showed a steady trend during 1990-2010, but then declined from 2011. As the Chinese economy enters a new normal, there has been a change from the previous situation of extensive development that required large amounts of raw materials. This represents an important reason for the continuous decline of freight volume on China's railways in recent years. However, since 2015, the turnover of railway freight has shown a trend of recovery, which reflects achievements made in the reform of railway freight organization, supply-side reform, and the development of a modern logistics industry. 

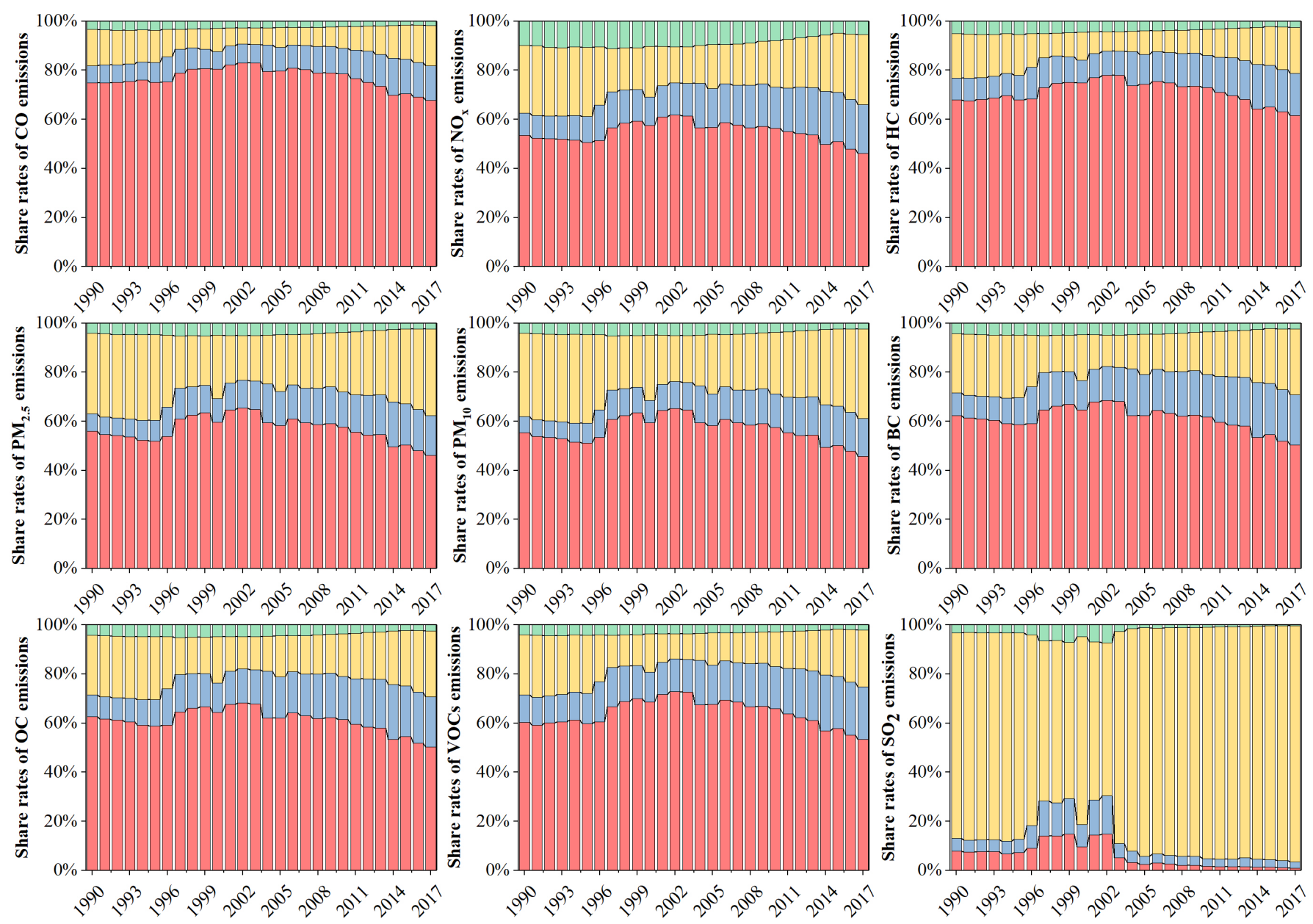

$\square$ Construction machinery

Agricultural machinery

Vessel

Locomotive

Fig. 6. Share rates of emissions from non-road equipment in China (1990-2017).

Comparison of Figs. 5 and 6 reveals that the contribution of agricultural machinery to the total pollutants from non-road equipment has also decreased with the reduction of agricultural machinery pollutant emissions. However, the pollutant emissions from construction machinery have not decreased as fast as from agricultural machinery. Consequently, the proportion of pollutant emissions from construction machinery in the total emissions from non-road equipment has increased gradually. With the slow increase in pollutant emissions from vessels, the proportion of pollutant emissions from vessels in the total emissions from non-road equipment has also increased correspondingly. Conversely, the proportion of pollutant emissions from diesel locomotives in the total emissions from non-road equipment has also decreased correspondingly.

As can be seen from Fig. 7, irrespective of whether in relation to $\mathrm{CO}, \mathrm{NO}_{x}, \mathrm{HC}, \mathrm{PM}_{2.5}, \mathrm{PM}_{10}, \mathrm{BC}$, OC, VOCs, or total emissions, the proportion of agricultural machinery emissions was $>50 \%$ and the contribution rate was the highest, followed very closely by vessels and construction machinery. This was because the total diesel power and diesel consumption of agricultural machinery were much greater than for other non-road equipment. In many urban areas, the emission of construction machinery was indeed higher than that of agricultural machinery, which was caused by not using agricultural machinery in urban areas. However, in rural areas, the emission of agricultural machinery was higher than that of construction machinery, which was caused by the large-scale use of agricultural machinery in rural areas. The total power and diesel consumption of vessels and construction machinery were similar, but the emission factor of vessels was higher than that of construction machinery, which resulted in the discharge of pollutant emissions from vessels being slightly higher than from construction machinery.

Vessels contributed the largest proportion of the total emissions of $\mathrm{SO}_{2}$, especially in coastal 


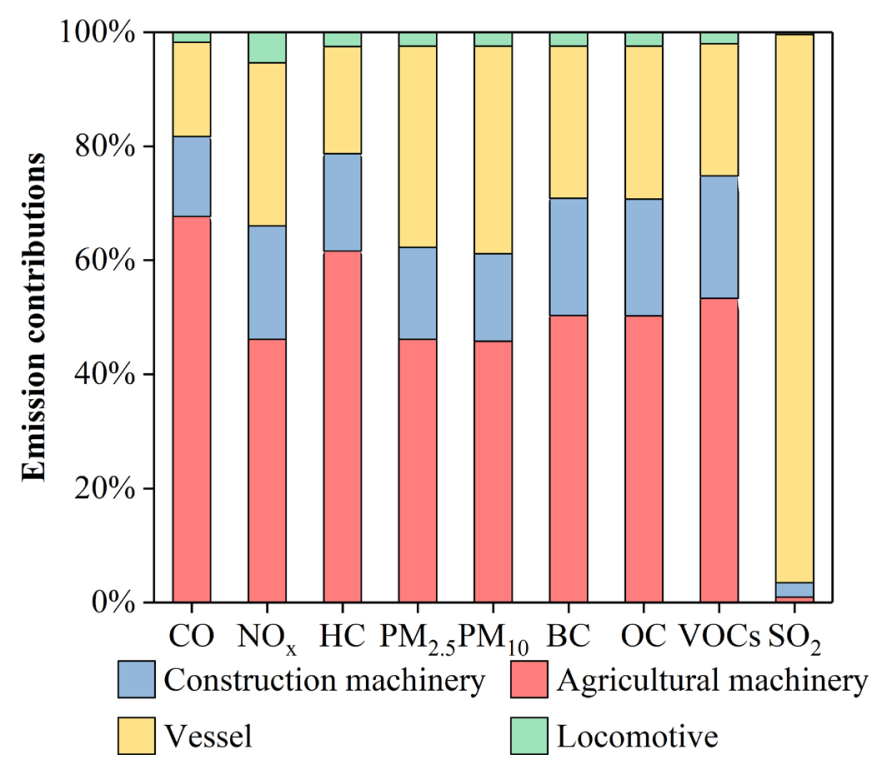

Fig. 7. Emission contributions of non-road equipment in China (2017).

provinces. This was because inland river vessels use low-quality diesel and coastal vessels mainly use heavy oil with higher sulphur content as fuel, unlike the diesel used by other machinery and equipment. Therefore, the $\mathrm{SO}_{2}$ emissions from vessels are much higher than from other non-road equipment, especially in coastal provinces. For example, Xu et al. (2019) established an emission inventory of non-road mobile sources in Jiangsu Province in 2015. Their results showed that the $\mathrm{SO}_{2}$ emission of vessels accounted for $90.4 \%$ of the total $\mathrm{SO}_{2}$ emissions from non-road mobile sources. Wang et al. (2018) investigated the characteristics of the impact of emissions from vessels on the air quality in China's coastal areas. Their results showed that emissions from vessels accounted for a considerable proportion of the $\mathrm{SO}_{2}$ and $\mathrm{NO}_{x}$ emissions in coastal provinces, while the Beijing-Tianjin-Hebei region was affected less by emissions from vessels.

\subsection{Comparison with Other Studies}

The emissions of non-road mobile sources reported in previous studies during the past several years were summarized and compared with those of our study, as shown in Fig. 8. From the perspective of national emissions, the estimated emissions of $\mathrm{NO}_{x}, \mathrm{CO}$, and $\mathrm{PM}$ from non-road mobile sources in this study were similar to those of Ning and Li (2016). However, the calculated result of $\mathrm{HC}$ emissions was lower than that of Ning and $\mathrm{Li}$ (2016), which reflects the selection of different $\mathrm{HC}$ emission factors. The estimated emissions of $\mathrm{NO}_{\mathrm{x}}, \mathrm{PM}$, and $\mathrm{HC}$ from non-road mobile sources in this study were similar to the results of Wang et al. (2016). However, the calculated result of CO emissions was lower than that of Wang et al. (2016), which also reflects the selection of different emission factors. Owing to the different types of non-road equipment involved, the emissions of $\mathrm{NO}_{x}, \mathrm{HC}, \mathrm{PM}$, and $\mathrm{SO}_{2}$ reported in the China Vehicle Environmental Management Annual Report (MEPC, 2018) were slightly higher than those calculated in this study. Limited by activity data, this study did not calculate the pollutant emissions of commercial aircraft.

$\mathrm{Li}$ (2016) did calculate the pollutant emissions of commercial aircraft, which is the main reason for the difference between the findings of that work and the results of this study. Different sources of activity data led to marked differences between the results of this study and the findings of Li (2017). However, Li (2017) used different calculation methods to conduct a more in-depth study of the pollutant emissions of vessels through use of activity data, making the pollutant emissions of vessels more accurate. As emissions of $\mathrm{SO} 2$ are derived largely from vessels, the $\mathrm{SO}_{2}$ emissions calculated by Li (2017) were higher than those calculated in this study.

From the perspective of regional emissions, we compared the emissions of non-road mobile source pollutants in Tianjin, Guangdong, Jiangsu, and Sichuan Provinces, the Yangtze River Delta, and the Beijing-Tianjin-Hebei region reported in different studies (Fig. 9). Zhang et al. (2017a), Huang et al. (2018), and Kui (2013) used a calculation method based on fuel consumption, which 

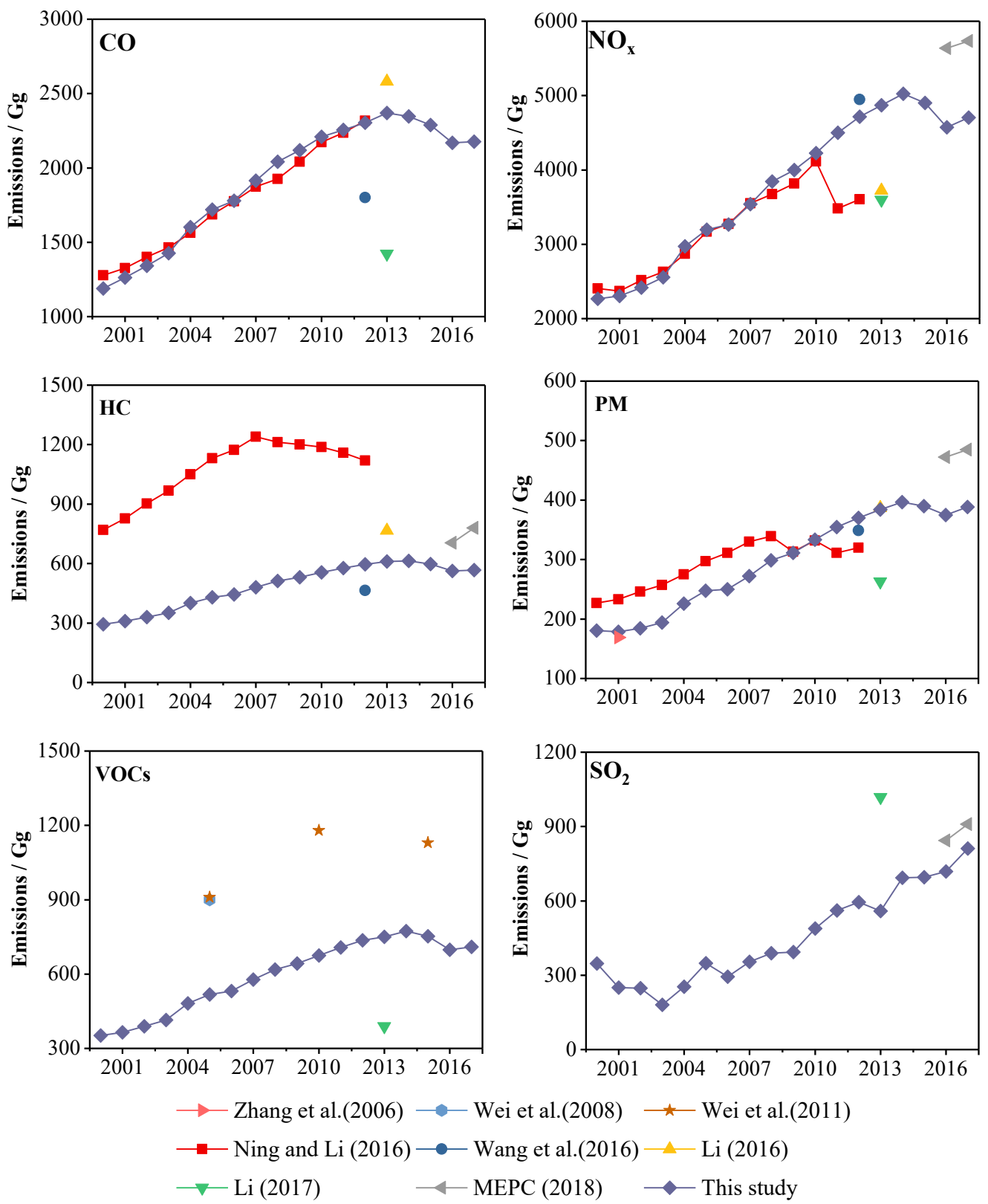

Fig. 8. Comparison of pollutant emissions from non-road mobile sources between different studies.

led to differences in the emissions. Bian et al. (2018) used field research methods to obtain activity data and emission factor data, and they established an emission inventory of non-road mobile sources in Guangdong Province. Xu et al. (2019) used a calculation method based on fuel consumption when calculating pollutant emissions from agricultural machinery and construction machinery, and they used a calculation method based on power when calculating pollutant emissions from vessels. Moreover, they also calculated the pollutant emissions of commercial aircraft. Fan et al. (2018) used field research methods to obtain more accurate activity data in Sichuan Province. In contrast, as this study calculated the nationwide non-road mobile source pollutant emissions, a method for obtaining activity data through field investigations was difficult to apply.

Compared with previous studies, different data processing methods were used to improve the completeness and accuracy of activity data. Moreover, according to different types of non-road equipment, different calculation methods and emission factors were selected to calculate the 

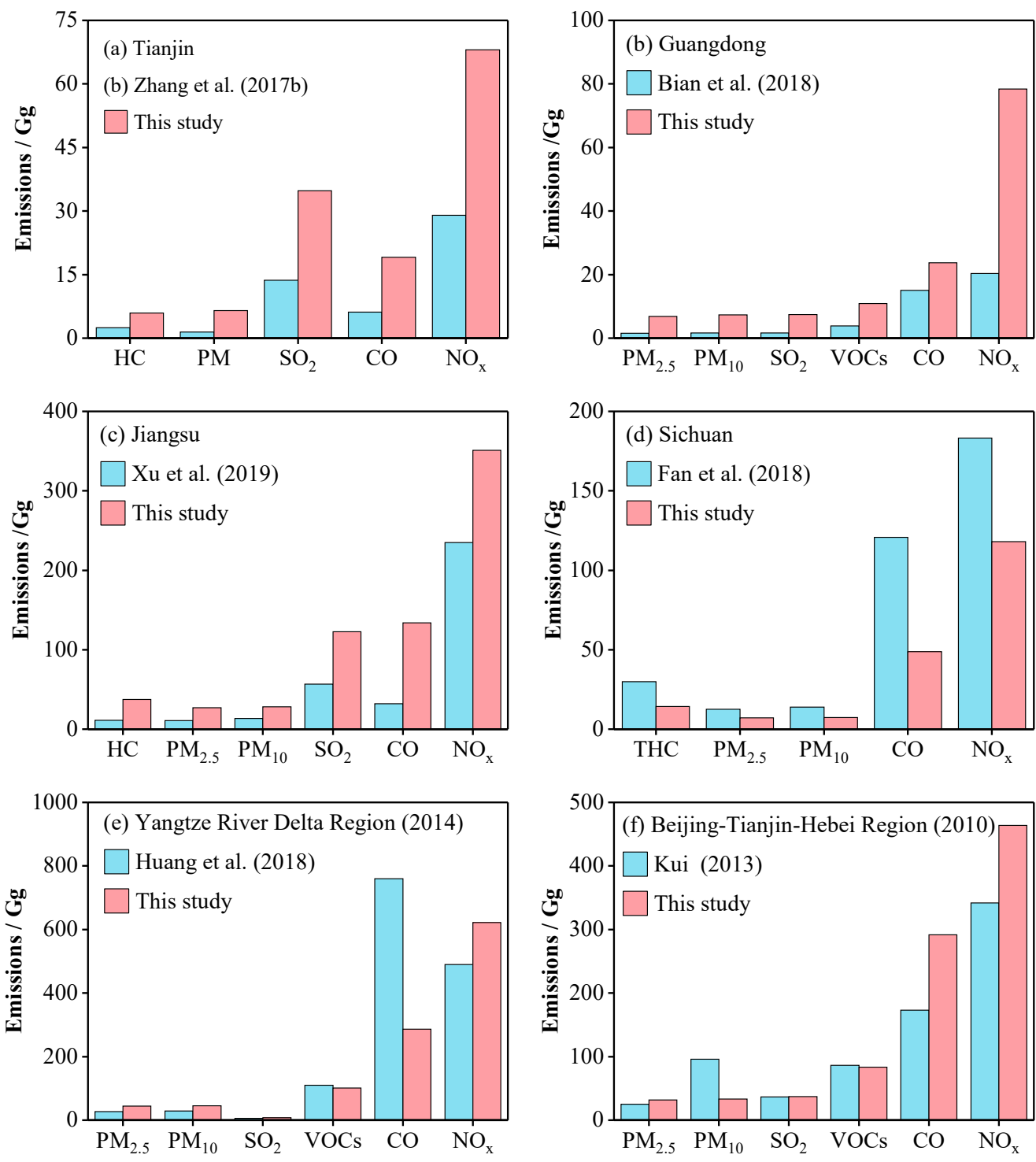

Fig. 9. Comparison of pollutant emissions from non-road mobile sources between different studies.

pollutant emissions to reduce the level of uncertainty of the emission inventory. Most importantly, this study estimated the overall emission trends of different types of non-road equipment based on a longer time span and a wider spatial scale, and the range of pollutants considered was relatively comprehensive.

\subsection{Uncertainty Analysis}

The uncertainty in this research originates primarily from three aspects: estimation of the population of non-road equipment, acquisition of activity data, and selection of actual emission factors. With regard to the estimation of the population of non-road equipment, China has not yet established a relevant registration and filing system for non-road equipment, and there are differences in statistics between different departments. There are also uncertainties in the activity data of the population of non-road equipment. In this study, the data of agricultural machinery population with different emission standards estimated by the survival curves of mechanical equipment improved the accuracy of agricultural machinery population data. Regarding the acquisition of activity data, owing to the large temporal span and wide spatial coverage of this study, together with the lack of relevant statistical data in certain areas in early China, there are some uncertainties in the activity data. This study used linear fitting to estimate missing data 
from known activity data to improve the accuracy and completeness of the activity data. In the selection of emission factors, there is a lack of accurate data on emission factors of non-road mobile sources in China. The emission factors selected in this study were average values recommended in the guidelines (MEPC, 2014), which do not adequately reflect the emission characteristics of non-road equipment under local actual working and operating conditions. Therefore, there are some uncertainties in the selection of emission factors. The uncertainty ranges $(95 \%$ confidence intervals; the calculation method was supplemented in the supplementary material) of the $\mathrm{CO}$, $\mathrm{NO}_{x}, \mathrm{HC}, \mathrm{PM}_{2.5}, \mathrm{PM}_{10}, \mathrm{BC}, \mathrm{OC}$, and VOC emission factors were $-10.9 \%$ to $9.9 \%,-21.1 \%$ to $17.4 \%$, $-8.3 \%$ to $7.7 \%,-33.1 \%$ to $24.9 \%,-32.7 \%$ to $24.7 \%,-33.0 \%$ to $24.8 \%, 34.0 \%$ to $25.4 \%$, and $-8.3 \%$ to $7.7 \%$, respectively. The coefficient of variation (CV) of the emission factors for non-road equipment varies by classification and pollutant. For example, the CV of agricultural machinery is in the range of $0.15-0.66$, which confirms the large uncertainty in the emission factor. Similar ranges of the $\mathrm{CV}$ are also observed for other non-road equipment. The representativeness of these data to the localities was not discussed in detail in the earlier studies, which might have weakened the accuracy of their estimated emission inventories. In addition, the estimation of $\mathrm{SO}_{2}$ emissions was based on a fuel-consumption-based material balance method. Its uncertainty comes from the assumption of the fuel sulphur content in addition to the fuel consumption estimated from the reference statistical yearbooks. In future work, extensive data collection of real-world activity including on-site surveys of activity and emissions when the equipment is on duty will be needed. Additionally, development of an extensive database of activity and emissions for non-road equipment would help reduce the uncertainty associated with these factors and thus improve the accuracy of emission inventory development.

\section{CONCLUSIONS}

We developed an emission inventory of nine air pollutants $-\mathrm{CO}, \mathrm{NO}_{x}, \mathrm{HC}, \mathrm{PM}_{2.5}, \mathrm{PM}_{10}, \mathrm{BC}, \mathrm{OC}$, VOCs, and $\mathrm{SO}_{2}$ - originating from four types of non-road mobile sources in mainland China between 1990 and 2017. Based on our estimates, these emissions generally grew over the study period, although the quantities of $\mathrm{CO}$ and $\mathrm{NO}_{x}$ reached an inflection point and then declined during the years 2010-2015, with the overall emissions resuming their upward trend in 2017. Varying stages of development for agriculture, transportation, and other industries across the nation resulted in geographically dispersed emissions from non-road mobile sources, with the North China Plain and Southeast China coastal area showing the highest concentrations and intensities. Moreover, among these sources, we identified agricultural machinery as the primary emitter of all of the investigated pollutants except $\mathrm{SO}_{2}$, which mainly arose from vessels and, to a lesser degree, construction machinery.

According to our emission inventory, the annual emissions of $\mathrm{CO}, \mathrm{NO}_{x}, \mathrm{HC}, \mathrm{PM}_{2.5}, \mathrm{PM}_{10}, \mathrm{BC}, \mathrm{OC}$, VOCs, and $\mathrm{SO}_{2}$ totalled 2176, 4704, 567, 368, 388, 208, 65.5, 710, and $811 \mathrm{Gg}$, respectively, in 2017-a 3-5-fold increase from 1990. Agricultural machinery accounted for the largest proportion ( $>50 \%$ ) of the total emissions, followed by vessels and construction machinery.

Our study reveals considerable deficiencies in inventorying the emissions of non-road mobile sources in China. Accurate emission factors, which can be obtained through further research on the emission characteristics, are urgently needed. Additionally, the registration system for these sources must be improved. Upon comparing our results with those from previous studies, we also discovered a lack of high-resolution emission inventories for non-road mobile sources in certain key regions, e.g., Shandong and Henan Provinces. Thus, to establish such inventories, assessments of emission characteristics as well as surveys of activity should be conducted in these areas.

In the future, we intend to focus on provinces with notable non-road mobile source emissions. We plan to evaluate the emission characteristics of these sources through actual tests and to collect a large volume of activity data through field research, thereby enabling us to develop an emission inventory with a high spatiotemporal resolution. Given the rise in non-road mobile source emissions, China must establish such inventories, both to identify specific sources and to quantify the generated pollutants. 


\section{ACKNOWLEDGMENTS}

This work was supported by the Beijing Natural Science Foundation (No. JQ19030), the Beijing Municipal Commission of Education (No. PXM2019_014213_000007), the School Level Cultivation Fund of Beijing Technology and Business University for Distinguished and Excellent Young Scholars (No. BTBUYP2020).

\section{SUPPLEMENTARY MATERIAL}

Supplementary material for this article can be found in the online version at https://doi. org/10.4209/aaqr.210003

\section{REFERENCES}

Bian, Y.H., Fan, X.L., Li, C., Ye, X., Wang, X.L., Huang, Z.J., Zheng, J.Y. (2018). A sector-based emission inventory and its uncertainty from non-road mobile machinery in Guangdong province, China. Acta Sci. Circumst. 38, 2167-2178 (in Chinese).

Cao, T.F., Durbin, T.D., Russell, R.L., Cocker, D.R., Scora, G., Maldonado, H., Johnson, K. C. (2016). Evaluations of in-use emission factors from off-road construction equipment. Atmos. Environ. 147, 234-245. https://doi.org/10.1016/j.atmosenv.2016.09.042

Chen, D.S., Wang, X.T., Li, Y., Lang, J.L., Zhou, Y., Guo, X.R., Zhao, Y.H. (2017). High-spatiotemporalresolution ship emission inventory of China based on AIS data in 2014. Sci. Total Environ. 609, 776-787. https://doi.org/10.1016/j.scitotenv.2017.07.051

Dallmann, T.R., Harley, R.A. (2010). Evaluation of mobile source emission trends in the United States. J. Geophys. Res. 115, D14305. https://doi.org/10.1029/2010JD013862

Desouza, C.D., Marsh, D.J., Beevers, S.D., Molden, N., Green, D.C. (2011). Real-world emissions from non-road mobile machinery in London. Atmos. Environ. 223, 117301. https://doi.org/10. 1016/j.atmosenv.2020.117301

Ding, D., Xing, J., Wang, S., Liu, K., Hao, J.M. (2019). Estimated contributions of emissions controls, meteorological factors, population growth, and changes in baseline mortality to reductions in ambient $\mathrm{PM}_{2.5}$ and $\mathrm{PM}_{2.5}$ related mortality in China, 2013-2017. Environ. Health Perspect. 127, 067009. https://doi.org/10.1289/EHP4157

Fan, S.B., Nie, L., Kan, R., Li, X.F., Yang, T. (2011). Fuel consumption-based exhaust emissions estimating from agricultural equipment in Beijing. J. Saf. Environ. 11, 145-148 (in Chinese).

Fan, W.B., Chen, J.H., Li, Y., Jiang, T., Sun, S., Wang, G., Liao, H.T., Jiang, T., Wu, K., Qian, J., Ye, H. (2018). Study on the non-road mobile source emission inventory for Sichuan province. China Environ. Sci. 38, 4460-4468 (in Chinese).

Gu, X.K., Yin, S.S., Lu, X., Zhang, H., Wang, L.L., Bai, L., Wang, C., Zhang, R.Q., Yuan, M.H. (2019). Recent development of a refined multiple air pollutant emission inventory of vehicles in the Central Plains of China. J. Environ. Sci. 84, 80-96. https://doi.org/10.1016/j.jes.2019.04.010

He, J.C, Wu, W.H., Xu, Y.Q. (2010). Energy consumption of locomotives in China railways during 1975-2007. J. Transp. Syst. Eng. Inf. Technol. 10, 22-27. https://doi.org/10.1016/S1570-6672( 09)60061-1

He, K.B., Wang, S.X., Zhang, Q. (2017). Technical manual for developing air pollutant emission inventory in urban areas. Ministry of Environmental Protection of the People's Republic of China, Beijing, China (in Chinese).

Hong, J., Kang, H., An, J., Choi, J., Hong, T., Park, H.S., Lee, D. (2021). Towards environmental sustainability in the local community: Future insights for managing the hazardous pollutants at construction sites. J. Hazard. Mater. 403, 123804. https://doi.org/10.1016/j.jhazmat.2020.123804

Huang, C., An, J.Y., Lu, J. (2018). Emission inventory and prediction of non-road machineries in the Yangtze River Delta Region, China. Environ. Sci. 39, 3965-3975 (in Chinese).

Jiang, M., Hu, X., Chunga, J., Lin, Z., Fei, R. (2020). Does the popularization of agricultural mechanization improve energy-environment performance in China's agricultural sector? J. Cleaner Prod. 276, 124210. https://doi.org/10.1016/j.jclepro.2020.124210 
Jiang, Z., Wang, B.Q., Niu, H.H., Liu, B.W., Hu, X.X. (2019). Study on non-road mobile sources emission inventory in Urumqi. Environ. Sci. Technol. 42, 182-186 (in Chinese).

Kean, A.J., Sawyer, R.F., Harley, R.A. (2000). A fuel-based assessment of off-road diesel engine emissions. J. Air Waste Manage. Assoc. 50, 1929-1939. https://doi.org/10.1080/10473289.20 00.10464233

Kui, X. (2013). Establishment of emission inventory of non-road mobile sources in Beijing-TianjinHebei region. 2013 Annual Conference of Chinese Society for Environmental Sciences, Kunming, China, pp. 1631-1637 (in Chinese).

Li, C. (2017). Emissions characteristics and future trends of non-road mobile Sources in China. Master thesis. South China University of Technology, Guangdong, China.

Li, M.Y. (2016). Research of mobile source inventories. Master thesis. Beijing Institute of Technology, Beijing, China.

Li, Y., Lv, C., Yang, N., Liu, H., Liu, Z. (2020). A study of high temporal-spatial resolution greenhouse gas emissions inventory for on-road vehicles based on traffic speed-flow model: A case of Beijing. J. Cleaner Prod. 277, 122419. https://doi.org/10.1016/j.jclepro.2020.122419

Lin, X.F., Xu, J.W., Liu, Y.H., Li, X.Y., Ma, J.L. (2019). Vehicle Survival Probability Curve and Law in Guangdong Province. Acta Sci. Nat. Univ. Sunyatseni 58, 65-73 (in Chinese).

Liu, Y.H., Liao, W.Y., Li, L., Huang, Y.T., Xu, W.J. (2017). Vehicle emission trends in China's Guangdong Province from 1994 to 2014. Sci. Total Environ. 586, 512-521. https://doi.org/10.1016/j.scitote nv.2017.01.215

Liu, Y.S., Ge, Y.S., Tan, J.W., Fu, M.L., Shah, A.N., Li, L.Q., Ji, Z., Ding, Y. (2018). Emission characteristics of offshore fishing ships in the Yellow Bo Sea, China. J. Environ. Sci. 65, 83-91. https://doi.org/10.1016/j.jes.2017.02.020

Lu, J., Huang, C., Hu, Q.Y., Yang, Q., Jing, B.L., Xia, Y., Lu, B., Tang, W., Lou, S.R., Tao, S.K., Li, L. (2017). Air pollutant emission inventory of non-road machineries in typical cities in eastern China. Environ. Sci. 38, 2738-2746 (in Chinese).

Ministry of Environmental Protection of the People' Republic of China (MEPC) (2014). Technical guidelines for the compilation of air pollutant emission inventories from non-road mobile sources (trial implementation). Ministry of Environmental Protection of the People's Republic of China, Beijing, China.

Ministry of Environmental Protection of the People's Republic of China (MEPC) (2018). China Vehicle Environmental Management Annual Report. Ministry of Environmental Protection of the People's Republic of China, Beijing, China.

National Bureau of Statistics (NBS) (2018). China Statistical Yearbook. China Statistics Press, Beijing, China.

Ning, Y.D., Li, H.L. (2016). Estimation for main atmospheric pollutants emissions from mobile sources in China. Chinese J. Environ. Eng. 10, 4435-4444 (in Chinese).

Pang, K.L., Zhang, K.S., Ma, S., Wang, F. (2020). Analysis of activity and its emissions trend for construction equipment in China. Environ. Sci. 41, 1132-1142 (in Chinese).

Song, Y.N. (2015). Research of Emission Inventory and Emission Character of Inland and Offshore Ships. Master thesis. Beijing Institute of Technology, Beijing, China.

Sun, S.D., Jiang, W., Gao, W.D. (2016). Vehicle emission trends and spatial distribution in Shandong province, China, from 2000 to 2014. Atmos. Environ. 147, 190-199. https://doi.org/10.1016/j.a tmosenv.2016.09.065

Sun, S., Sun, L., Liu, G., Zou, C., Wang, Y., Wu, L., Mao, H. (2021). Developing a vehicle emission inventory with high temporal-spatial resolution in Tianjin, China. Sci. Total Environ. 776, 145873. https://doi.org/10.1016/j.scitotenv.2021.145873

Wang, F., Li, Z., Zhang, K.S., Di, B.F., Hu, B.M. (2016). An overview of non-road equipment emissions in China. Atmos. Environ. 132, 283-289. https://doi.org/10.1016/j.atmosenv.2016.0 2.046

Wang, Y.L., Li, C., Huang, Z.J., Yin, X.H., Ye, X., Wang, X.L., Zheng, J.Y. (2018). Impact of ship emissions on air quality over Chinese waters in 2013. Acta Sci. Circumst. 38, 2157-2166 (in Chinese).

Wei, W., Wang, S.X., Chatani, S., Klimont, Z., Cofala, J., Hao, J.M. (2008). Emission and speciation of non-methane volatile organic compounds from anthropogenic sources in China. Atmos. Environ. 42, 4976-4988. https://doi.org/10.1016/j.atmosenv.2008.02.044 
Wei, W., Wang, S.X., Hao, J.M., Cheng, S.Y. (2011). Projection of anthropogenic volatile organic compounds (VOCs) emissions in China for the period 2010-2020. Atmos. Environ. 45, 68636871. https://doi.org/10.1016/j.atmosenv.2011.01.013

Wu, Y., Zhang, S.J., Hao, J.M., Liu, H., Wu, X.M., Hu, J.N., Walsh, M.P., Wallington, T.J., Zhang, K.M., Stevanovic, S. (2017). On-road vehicle emissions and their control in China: A review and outlook. Sci. Total Environ. 574, 332-34. https://doi.org/10.1016/j.scitotenv.2016.09.040

Xie, Y.S., Zheng, X.M. (2016). Atmospheric pollutant emission inventory from non-road mobile sources in Nanjing and its characteristics. Pollut. Control Technol. 29, 47-51 (in Chinese).

Xu, W.W., Xu, X.J., Yin, C.Q. (2019). Study on non-road mobile source emission inventory for Jiangsu province. Energy Environ. Prot. 33, 59-64 (in Chinese).

Yang, W., Yu, C.Y., Yuan, W., Wu, X.Y., Zhang, W., Wang, X.M. (2018). High-resolution vehicle emission inventory and emission control policy scenario analysis, a case in the Beijing-TianjinHebei (BTH) region, China. J. Cleaner Prod. 203, 530-539. https://doi.org/10.1016/j.jclepro.20 18.08.256

Ye, S.Q., Zheng, J.Y., Pan, Y.Y., Wang, S.S., Lu, Q., Zhong, L.J. (2014). Marine emission inventory and its temporal and spatial characteristics in Guangdong Province. Acta Sci. Circumst. 34, 537-547 (in Chinese).

Zachariadis, T., Samaras, Z., Zierock, K. (1995). Dynamic modeling of vehicle populations: An engineering approach for emissions calculations. Technol. Forecasting Social Change 50, 135149. https://doi.org/10.1016/0040-1625(95)00057-H

Zawacki, M., Baker, K.R., Phillips, S., Davidson, K., Wolfe, P. (2018). Mobile source contributions to ambient ozone and particulate matter in 2025. Atmos. Environ. 188, 129-141. https://doi.org/ 10.1016/j.atmosenv.2018.04.057

Zhang, J.W., Xian, Y., Chen, B.Z. (2017a). Study on the emission inventory from mobile source in Nanchang. Acta Sci. Circumst. 37, 2449-2458 (in Chinese).

Zhang, L.J., Zheng, J.Y., Yin, S.S., Peng, K., Zhong, L.J. (2010). Development of non-road mobile source emission inventory for the Pearl River Delta region. Environ. Sci. 31, 886-891 (in Chinese).

Zhang, Q., Klimont, Z., Streets, D.G., Huo, H., He, K.B. (2006). Emission model of PM sourced from human activities in China and emission inventory in 2001. Prog. Nat. Sci. 16, 223-231 (in Chinese).

Zhang, Q., Zheng, Y.X., Tong, D., Shao, M., Wang, S.X., Zhang, Y.H., Xu, X.D., Wang, J.N., He, H., Liu, W.Q. (2019). Drivers of improved $\mathrm{PM}_{2.5}$ air quality in China from 2013 to 2017. Proc. Natl. Acad. Sci. U.S.A. 116, 24463-24469. https://doi.org/10.1073/pnas.1907956116

Zhang, Q., Tong, P., Liu, M., Lin, H., Yun, X., Zhang, H., Tao, W., Liu, J., Wang, S., Tao, S., Wang, X. (2020). A WRF-Chem model-based future vehicle emission control policy simulation and assessment for the Beijing-Tianjin-Hebei region, China. J. Environ. Manage. 253, 109751. https://doi.org/10.1016/j.jenvman.2019.109751

Zhang, Y., Michel, A., Li, D., Zhang, X., Wu, L., Zhang, Y. J., Ma, C., Zhou, C., Mao, H.J. (2017b) Development of a non-road mobile source emissions inventory for Tianjin. Environ. Sci. 38, 4447-4453 (in Chinese) 